\title{
Optimization of bacterial nanocellulose fermentation using recycled paper sludge and development of novel composites
}

\author{
Francisco A. G. Soares da Silva ${ }^{1}$ • Marta Fernandes ${ }^{2}$ - António Pedro Souto ${ }^{2} \cdot$ Eugénio C. Ferreira $^{1}$. \\ Fernando Dourado ${ }^{1}$ (D) $\cdot$ Miguel Gama $^{1}$
}

Received: 2 May 2019 / Revised: 27 August 2019 / Accepted: 8 September 2019 /Published online: 24 October 2019

(C) Springer-Verlag GmbH Germany, part of Springer Nature 2019

\begin{abstract}
In this work, recycled paper sludge (RPS), composed of non-recyclable fibres, was used as a carbon source for bacterial nanocellulose (BNC) production. The biomass was enzymatically hydrolysed with Cellic CTec 2 to produce a sugar syrup with $45.40 \mathrm{~g} / \mathrm{L}$ glucose, $1.69 \mathrm{~g} / \mathrm{L}$ cellobiose and $2.89 \mathrm{~g} / \mathrm{L}$ xylose. This hydrolysate was used for the optimization of BNC fermentation by static culture, using Komagataeibacter xylinus ATCC 700178, through response surface methodology (RSM). After analysis and validation of the model, a maximum BNC yield $(5.69 \mathrm{~g} / \mathrm{L}$, dry basis) was obtained using $1.50 \% \mathrm{~m} / \mathrm{v}$ RPS hydrolysate, $1.0 \%$ $\mathrm{v} / \mathrm{v}$ ethanol and $1.45 \% \mathrm{~m} / \mathrm{v}$ yeast extract/peptone (YE/P). Further, the BNC obtained was used to produce composites. A mixture of an amino-PolyDiMethylSiloxane-based softener, polyethyleneglycol (PEG) 400 and acrylated epoxidized soybean oil (AESO), was incorporated into the BNC membranes through an exhaustion process. The results show that BNC composites with distinct performances can be easily designed by simply varying the polymers percentage contents. This strategy represents a simple approach towards the production of BNC and BNC-based composites.
\end{abstract}

Keywords Bacterial nanocellulose $\cdot$ Sludge $\cdot$ Composites $\cdot$ Soybean $\cdot$ Polymers

\section{Introduction}

The main residue of the pulp and paper industry is the sludge from the primary and secondary effluents treatment (Kamali and Khodaparast 2015). Currently, 35\% of the material entering the pulp and paper mills becomes a residue, with $56 \%$ of which being used for energy recovery, leaving $44 \%$ of the residues without an environmentally and economically suitable solution (Scott and Smith 1995). Landfill disposal is a

Francisco A. G. Soares da Silva and Marta Fernandes contributed equally to this work.

Electronic supplementary material The online version of this article (https://doi.org/10.1007/s00253-019-10124-6) contains supplementary material, which is available to authorized users.

Fernando Dourado

fdourado@deb.uminho.pt

1 CEB - Centre of Biological Engineering, University of Minho, Campus de Gualtar, 4710-057 Braga, Portugal

2 Centre for Textile Science and Technology, University of Minho, Campus de Azurém, 4800-058 Guimarães, Portugal costly and ecologically damaging solution. Hence, finding novel alternatives to the use of this sludge represents an emerging priority in the paper industry. Alternatives to treat paper sludge are being studied. Marques et al. 2008a, b, 2009 and Gomes et al. 2016 exploited the high lignocellulosic content sludge material as carbon source to produce lactic acid and bioethanol (Marques et al. 2008a, b, 2009; Prasetyo and Park 2013; Gomes et al. 2016). Bacterial nanocellulose (BNC), a Biotech nanocellulose, features high porosity, high crystallinity, high degree of polymerization, high mechanical strength in wet state, high water holding capacity, low density, biocompatibility, non-toxicity and biodegradability. Due to the high potential of BNC, numerous applications have been studied, such as in the biomedical field as tissue regeneration and drug delivery systems; in the textile and paper industries for fibre composites and coatings; and in the food and cosmetic industries as an emulsifier (Klemm et al. 2001; Chawla et al. 2009; Müller et al. 2013; Nimeskern et al. 2013; Lee et al. 2014; Shi et al. 2014; Rajwade et al. 2015). However, the largescale production of BNC still represents a challenge, due to ineffective fermentations systems, high operation cost and low BNC yields (Campano et al. 2016). Several 
efforts have focused on the use of low-value raw materials as a nutrient source for bacterial fermentation. Examples include the use of rotten fruits, milk whey carob and haricot bean, corn steep liquor as nitrogen source, molasses as carbon source, waste beer yeast, beverage industrial waste, fruit peels, rice bark and fruit juices as food industrial waste (Yamanaka et al. 1989; Hong et al. 2011; Tsouko et al. 2015; Campano et al. 2016; Fan et al. 2016). Other residues such as distillery effluents, waste glycerol from biodiesel, waste fibre sludge, cotton-based waste textiles and wastewaters have been tested (Hong et al. 2012; Huang et al. 2016; Chen et al. 2017; Cheng et al. 2017).

In this work, recycled paper sludge (RPS) was characterized and used as a raw material for BNC production. An enzymatic RPS hydrolysate was obtained and used as a carbon source in the static culture fermentation process. Central composite design response surface methodology (CCD-RSM) was performed, using the strain K. xylinus ATCC 700178. Further, the BNC membranes were used for the development of nanocomposites, using formulations that includes (i) a commercial softener based on polydimethylsiloxane (conferring malleability, robustness and softness); (ii) PEG400 (as a plasticizer, allowing to obtain a product with greater elasticity as well as contributing to improve the interfacial adhesion between the BNC and the other polymers) and (iii) acrylated epoxidized soybean oil (AESO) (yielding a high biobased content BNC composite with hydrophobic character) ( $\mathrm{Li}$ et al. 2019). AESO is obtained from soybean oil, a renewable resource abundantly available, via epoxidation and acryloilation. It contains three highly reactive functionalities, double $(\mathrm{C}=\mathrm{C})$ bonds, $-\mathrm{OH}$ groups and epoxy rings. The $\mathrm{C}=\mathrm{C}$ bonds in AESO is capable of self-polymerizing and copolymerizing with other components via a free-radical initiation, forming a three-dimensional network (Yudianti and Karina 2012). A simple and effective approach was developed, based on the use of an exhaustion process, aiming to produce BNC nanocomposites.

\section{Materials and methods}

\section{Bacterial strain}

Komagaebacter xylinus ATCC 700178 (from the American Type Culture Collection) was used for the fermentation assays. The strain was maintained in Hestrin-Schramm culture medium (HS) in solid state with $2.0 \%(\mathrm{w} / \mathrm{v})$ agar (Acros Organics).

\section{Enzymatic hydrolysis of RPS}

The recycled paper sludge (RPS) was kindly provided from EUROPAC (Viana do Castelo, Portugal). The RPS fibres suspension, at a concentration of $16.0 \%(\mathrm{~m} / \mathrm{v})$, was pre-treated for the neutralization of carbonates by adding $\mathrm{HCl}$ to a final concentration of $4.0 \%(\mathrm{v} / \mathrm{v})$ (Fischer Chemical) (Marques et al. 2009; Gomes et al. 2016). Then, the fibres were washed by filtration with distilled water to remove the acid. This operation was repeated three times. Afterwards, the solids were dried at $37{ }^{\circ} \mathrm{C}$ for $48 \mathrm{~h}$. The dried RPS solids were then submitted to an enzymatic hydrolysis for degradation of the cellulose and hemicellulose as follows: a sludge suspension as prepared with a consistency of $23 \%(\mathrm{~m} / \mathrm{v})$, in acetic acid/ sodium acetate $(0.1 \mathrm{M})$ buffer; this mixture was sterilized at $121{ }^{\circ} \mathrm{C}$ for $15 \mathrm{~min}$. Afterwards, $1.65 \%$ (v/v) of Cellic CTec 2 (Novozymes), with an activity of $80 \mathrm{FPU} / \mathrm{mL}$ (corresponding to an enzyme dosage of $20 \mathrm{FPU} / \mathrm{g}$ cellulose), was used. Before use, the cellulase was diluted (ratio of 1:1 v/v) with the buffer solution and filtered using a sterile polyethersulfone filter (from Biofilter), under aseptic conditions, into the sterilized RPS suspension. The mixture was maintained at $280 \mathrm{rpm}$ and at $50{ }^{\circ} \mathrm{C}$, for $120 \mathrm{~h}$, in an orbital incubator (Heidolph Inkubator 1000). After the enzymatic hydrolysis, the suspension was filtered to remove the final solid residue. The obtained hydrolysate was sterilized at $121^{\circ} \mathrm{C}$ for $20 \mathrm{~min}$ and stored until further use. To evaluate the recovery yield of sugars, the following equation was used (Kim et al. 2010).

Yield recovery sugars $(\% m / m)=\frac{\text { glucose }\left(\frac{g}{L}\right) * \text { hydrolysate }(L) * \operatorname{correction} \text { factor }}{\operatorname{sludge}(g) * \operatorname{solids}(\%, m / v) * \operatorname{cellulose}(\%, m / m)}+\frac{\text { xylose }\left(\frac{g}{L}\right) * \text { hydrolysate }(L) * \text { correction factor }}{\operatorname{sludge}(g) * \operatorname{solids}(\%, m / v) * \text { hemicellulose }(\%, m / m)}$

where the correction factor for the glucose is $\frac{160 \text { glucan }}{180 \text { glucose }}=0.9$ and for the xylose is $\frac{132 \text { xylan }}{150 \text { xylose }}=0.88$.

Glucose and xylose were quantified by high-performance liquid chromatography (HPLC) as described further below. The amount of cellulose and hemicellulose in RPS were quantified according to the national renewable energy laboratory (NREL) protocol for the determination of structural carbohydrates and lignin in biomass (Sluiter et al. 2008). Summing up,
RPS samples were submitted to an acid hydrolysis, comprising two stages. Firstly, $5 \mathrm{~mL}$ of $\mathrm{H}_{2} \mathrm{SO}_{4}$ at $72 \% \mathrm{v} / \mathrm{v}$ was added to $0.5 \mathrm{~g}$ of RPS, where the suspension was maintained for $1 \mathrm{~h}$ at $30{ }^{\circ} \mathrm{C}$. Afterwards, the resulted suspension was diluted until $\mathrm{H}_{2} \mathrm{SO}_{4}$ was at $4 \% \mathrm{v} / \mathrm{v}$ and autoclaved for $1 \mathrm{~h}\left(121^{\circ} \mathrm{C}\right)$. In the end, the suspension was filtered, and the sugars of the resulting hydrolysate were measured by HPLC, for the calculus of $\%$ of cellulose and hemicellulose (Sluiter et al. 2008). 


\section{Inoculum preparation and BNC static culture fermentation}

K. xylinus ATCC 700178 cells were grown in $1 \mathrm{~L}$ conical flasks, containing $100 \mathrm{~mL}$ of Hestrin-Schramm culture medium (HS) (Hestrin and Schramm 1954) containing the following components (in $\% \mathrm{~m} / \mathrm{v}$ ): 2.0 glucose (Fluka), 0.5 peptone (Himedia), 0.5 yeast extract (Fisher), 0.339 disodium phosphate di-hydrated (Panreac) and 0.126 citric acid (Panreac). HS medium was autoclaved at $121^{\circ} \mathrm{C}$ for $20 \mathrm{~min}$. After inoculation, the culture was incubated for $48 \mathrm{~h}$ under static conditions. The formed cellulose pellicle was vigorously shaken to release the bacteria entrapped within the cellulose matrix into the residual medium, which was used for further inoculations at $10 \%(\mathrm{v} / \mathrm{v})$ of the final fermentation volume. The inoculated fresh culture media was incubated in $250 \mathrm{~mL}$ beakers at $30{ }^{\circ} \mathrm{C}$ for 15 days (at a fixed culture medium depth of $1.5 \mathrm{~cm}$ ). RPS culture medium thus contains the same components as HS medium with exception of glucose, which was replaced with the RPS hydrolysate. After fermentation, the BNC membranes were collected and purified and the production yield (in $\mathrm{g}$ dry mass/L culture media) was determined as described below.

\section{Optimization of BNC fermentation using central composite design-response surface methodology}

Response surface methodology was used for the culture medium optimization of BNC production. This methodology allows for the development of an adequate functional relationship between a response and a number of associated controls. To achieve this, Design-Expert software 7.1.5 (Stat-Ease. Inc. USA. Windows operating system) was used either for the experimental design and central composite design-response surface methodology (CCD-RSM) analysis of RSP medium with K. xylinus ATCC 700178. All experiments were performed independently, following the sequential order as displayed on supplementary material (Supplementary material, Table S2). Tables 1 and S2 show the experimental design used for the response surface optimization. Each run from Table S2 was performed in triplicate and all combinations of the fermentation medium included a fixed amount of $3.39 \mathrm{~g} / \mathrm{L} \mathrm{Na}_{2} \mathrm{HPO}_{4}$ and $1.26 \mathrm{~g} / \mathrm{L}$ citric acid and a fixed initial $\mathrm{pH}$ value of 5.5 (see supplementary material). The model was evaluated using Fisher's statistical test for analysis or variance (ANOVA). Finally, three-dimensional curves of the response surfaces were generated using the same statistical approach.

\section{Bacterial nanocellulose yield}

After 15 days of fermentation, BNC membranes were washed with $\mathrm{NaOH} 0.1 \mathrm{M}$ (Panreac), at room temperature, to remove culture medium residues and trapped cells. Afterwards, the membranes were washed with distilled water, also at room temperature, until the $\mathrm{pH}$ became that of the distilled water. The washed membranes were then weighed before and after drying to constant mass, at $37^{\circ} \mathrm{C}$, to calculate the volumetric yield of $\mathrm{BNC}(\mathrm{g} / \mathrm{L})$.

\section{Analytical methods}

\section{Total sugar and protein quantification}

High-performance liquid chromatography (HPLC), equipped with a Metacarb $87 \mathrm{H}$ column (300, $7.8 \mathrm{~mm}$, Varian, USA), PU-2080 Plus pump (JASCO), DG-2080-53 degasser (JASCO), AS2057-Plus automatic sample injector (JASCO) and a 2031 Plus RI detector (JASCO), was used to identify and quantify the sugars' concentration. A mobile phase $(5 \mathrm{mM}$ $\mathrm{H}_{2} \mathrm{SO}_{4}$ ) at a flow rate of $0.05 \mathrm{ml} / \mathrm{min}$ and column temperature of $35{ }^{\circ} \mathrm{C}$ was used. The injected volume was $20 \mu \mathrm{L}$. The concentration of cellobiose, glucose and xylose were determined based on calibration curves obtained using the pure compounds with concentrations ranging from 0.001 to $2.5 \%$ $(\mathrm{m} / \mathrm{v})$

\section{BNC composites production}

\section{Materials}

Soybean oil, epoxidized acrylate (Sigma-Aldrich), Lauryl methacrylate (Acros Organics, 97\%), 1,6-hexanodiol diacrylate (Sigma-Aldrich, 80\%), Tri (propylene glycol) diacrylate (Sigma-Aldrich), tert-Butyl peroxybenzoate (Sigma-Aldrich, 98\%) and Polyethylene glycol 400 (Merck Millipore) were used as received without further purification.

The softener Persoftal MS Conc.01 (Tanatex Chemicals) consists of an non-ionic aqueous dispersion of Siloxanes and
Table 1 Level of factors chosen for the experimental CCD-RSM

\begin{tabular}{lllllll}
\hline Factor & Name & Low actual & $\begin{array}{l}\text { High } \\
\text { actual }\end{array}$ & Low coded $(-1)$ & High coded $(+1)$ & Mean \\
\hline A & RPS \% (w/v) & 1.00 & 5.50 & 0.38 & 4.62 & $2.50 \pm 1.57$ \\
B & Ethanol \% (v/v) & 1.00 & 3.50 & 0.15 & 4.35 & $1.93 \pm 0.94$ \\
C & YE/P \% (w/v) & 0.50 & 1.50 & 0.29 & 1.71 & $1.40 \pm 0.77$ \\
\hline
\end{tabular}


Silicones, 3-((2-aminoethyl)amino)propyl Me, diMe, hydroxy-terminated (10-20\%), with density of $0.99 \mathrm{~g} \mathrm{~cm}^{-3}$ $\left(23{ }^{\circ} \mathrm{C}\right)$ and viscosity of $405 \mathrm{mPa} \mathrm{s}\left(23{ }^{\circ} \mathrm{C}\right)$.

\section{BNC composites}

BNC membranes were used as a scaffold for the production of composites by the incorporation of a mixture of Persoftal MS Conc.01, polyethyleneglycol (PEG) 400 and acrylated epoxidized soybean oil (AESO). AESO has a low cross-linking density and thus inferior mechanical strength due to the existence of long aliphatic chains and low degree of unsaturation in AESO molecules. Also, it has high viscosity at room temperature that restricts its processability (Yudianti and Karina 2012). To reduce these limitations, a mixture containing different reactive monomers added to AESO (coded "AESO mixture", Table 2) was prepared as follows (in mass percentages): AESO $(50 \%)$, lauryl methacrylate $(38.5 \%), 1,6$-hexanodiol diacrylate $(5 \%)$, tri(propylene glycol) diacrylate $(5 \%)$ and the initiator tert-Butyl peroxybenzoate $(1.5 \%)$. This mixture was prepared $24 \mathrm{~h}$ prior to use where all products were mixed and then placed under magnetic stirring for $1 \mathrm{~h}$ at $500 \mathrm{rpm}$.

For the composites' production, purified (as described above) wet BNC membranes with about $3.0 \mathrm{~cm}$ in thickness, with a size of $13.0 \times 16.0 \mathrm{~cm}$ and weighting $700 \mathrm{~g}$ were used. The membranes were first mechanically pressed to remove the excess of adsorbed water to a final wet mass of $135 \mathrm{~g}$, corresponding to $5.5 \%$ dry mass in BNC and a thickness of around $0.5 \mathrm{~cm}$. The compressed membranes were then treated with the different polymers at different combination, by an exhaustion process, as detailed in Table 2.

For this, the pressed BNC membranes were placed inside the stainless steel cups and the polymers' mixture was added at a mass ratio of BNC:polymer mixture of 1:10.

The exhaustion process was then carried out in an Ibelus machine equipped with an infrared heating system, using stainless steel cups with a capacity of approximately $220 \mathrm{~cm}^{3}$, with a rotation of $50 \mathrm{rpm}$, for 40 cycles. The desired temperature $\left(60{ }^{\circ} \mathrm{C}\right)$ was achieved using a gradient of

Table 2 Formulations used in the production of BNC composites

\begin{tabular}{llll}
\hline Sample & $\begin{array}{l}\text { Persoftal } \\
\text { MS }(\mathrm{g})\end{array}$ & $\begin{array}{l}\text { PEG } \\
400(\mathrm{~g})\end{array}$ & $\begin{array}{l}\text { AESO } \\
\text { mixture }(\mathrm{g})\end{array}$ \\
\hline BNC & - & - & - \\
BNC-S* & 75 & 0 & 0 \\
BNC-S/PEG400 & 60 & 15 & 0 \\
BNC-S/PEG400/AESO & 20 & 20 & 35 \\
\hline
\end{tabular}

*S Softener
$2{ }^{\circ} \mathrm{C} \mathrm{min}{ }^{-1}$. The treatment lasted for 2 days at $60{ }^{\circ} \mathrm{C}$, after which the samples were oven dried (WTC binder oven) at $90{ }^{\circ} \mathrm{C}$ for $24 \mathrm{~h}$ (until constant mass), followed by a curing step for $3 \mathrm{~h}$ at $180^{\circ} \mathrm{C}$.

\section{BNC composites characterization}

\section{ATR-FTIR analysis}

ATR-FTIR spectra of the BNC and BNC composites were collected in the attenuated total reflection mode (ATR) at a spectral resolution of $16 \mathrm{~cm}^{-1}$, with 60 scans, over the range $650-4000 \mathrm{~cm}^{-1}$ at room temperature, using a Nicolet Avatar 360 FTIR spectrophotometer (Madison, USA).

\section{Scanning electron microscopy}

The surface morphology and cross section of the BNC and BNC composites was examined using an ultra-high-resolution field emission gun scanning electron microscopy (SEM) instrument (NOVA 200 Nano SEM, FEI Co., OR, USA). To analyse the cross section, the samples were fractured after immersion in liquid nitrogen. All samples were coated with a thin layer of gold palladium.

\section{Wettability}

The wettability of the samples was characterized via static contact angle measurements, performed using a Dataphysics instrument (Filderstadt, Germany) with the software OCA20 (Germany) with a video system for the capture of images in static mode, using the sessile drop method. A drop of $5 \mu \mathrm{L}$ of distilled water was positioned on the composite's surface with a microliter syringe and observed over time for $180 \mathrm{~s}$. At least five measurements at different places were taken for each sample. To measure the angle formed at the liquid/solid interface, images were captured with a special charge-coupled device camera that takes an image every $0.04 \mathrm{~s}$.

\section{Mechanical properties}

For the tensile strength measurements, the full width of the sample $(25 \mathrm{~mm})$ was fixed and a length that allows an initial distance between the clamps of the strength tester equipment (Hounsfield HSK100) of $100 \mathrm{~mm}$ was set out between grips; the samples were then submitted to tensile. Three samples of each material were tested at a constant speed of $100 \mathrm{~mm} \mathrm{~min}^{-1}$. 


\section{Results}

\section{Optimization of the BNC production using RPS hydrolysates}

The RPS batch from EUROPAC used in this study contains $30 \%$ cellulose and $18 \%$ hemicellulose (Supplementary material, Table S1). After enzymatic hydrolysis with Cellic CTec2, a sugar syrup with $45.40 \mathrm{~g} / \mathrm{L}$ of glucose, $1.69 \mathrm{~g} / \mathrm{L}$ of cellobiose and $2.89 \mathrm{~g} / \mathrm{L}$ of xylose was obtained. Thus, a conversion of the syrup's biomass into $>60 \%$ glucose was achieved, the cellobiose content (unavailable for fermentation) being residual. Although the saccharification process was not optimized, the syrup obtained is satisfactory for the purpose of this study. In the work by Marques et al. (2008a, b), also using recycled paper sludge, a similar degree of saccharification and final concentration of glucose, xylose and cellobiose was reported. RSM is a factorial design methodology (Table 1) where 3D surface curves (Fig. 1) can be generated by linear and quadratic effects and two-way interactions between the factors (Bilgi et al. 2016). CCD-RSM was used for the optimization of BNC fermentation with K. xylinus ATCC 700178 , using RPS hydrolysate as the carbon source. The experimental runs as obtained by CCD-RSM are shown in table S2 (supplemental material). The results of the BNC yield from each run represent the average of triplicates. Runs 1, 4, 6, 12 and 13 (Supplementary material, Table S2), which represent the centre points of the design, yielded similar BNC productivity $(p>0.05)$. The highest yield $(5.69 \mathrm{~g} / \mathrm{L})$ was obtained using $1.5 \% \mathrm{~m} / \mathrm{v}$ RPS; $1.0 \% \mathrm{v} / \mathrm{v}$ etOH; $1.0 \% \mathrm{~m} / \mathrm{v}$ YE/P (run 2). Under the conditions of this fermentation, all carbon (mostly glucose, supplementary material, Table S2) from RPS was consumed after 15 days fermentation (98\% of glucose equivalent consumption) (data not shown). On the other hand, high RPS hydrolysate concentrations inhibit BNC production (Supplementary material, run 11, table S2).

The following table displays the ANOVA analysis of the model built by CCD-RSM for BNC yield optimization of $K$. xylinus with RPS hydrolysate, where the significance of each parameter (RPS hydrolysate, YE/P and ethanol) and the interaction between them were assessed (Table 3; Fig. 1).

$$
\begin{aligned}
B N C \text { yield }= & 6.91-2.04 * R P S-0.937 * E t O H+3.06 * Y E / P \\
& +0.170 * R P S * E t O H-0.156 * R P S * Y E / P \\
& +0.451 * E t O H * Y E / P \\
& +0.135 * R^{2} S^{2}-0.0349 * E^{2} O H^{2}-1.18 * Y E / P^{2}
\end{aligned}
$$

$\{$ Degree of freedom $=9 ; F$-value $=252.64 ; p$ value $<$ $0.0001 ; R^{2}=0.9978 ; \mathrm{RPS}$ and $\mathrm{YE} / \mathrm{P}$ in $\%(\mathrm{w} / \mathrm{v})$ and $\mathrm{EtOH}$ in $\%(\mathrm{v} / \mathrm{v})\}$

From these assays, a second polynomial order model (Eq. 2) was originated that best fitted the experimental data. This allowed estimating the optimal response (the maximum BNC yield). Analysis of variance (ANOVA) analysis of the CCD experiments ((Supplementary material, table $\mathrm{S} 2)$ ) is represented in Table 3. ANOVA statistical analysis was carried out followed by Fisher's least significant difference (LSD), where $F$ and $p$ values indicate that the model and the controlled parameters "A-RPS", "C-YE/P", "AB", "AC", "BC", " $\mathrm{A}$ " " and " $\mathrm{C}$ " " were significant $(p<0.04)$ (Table 3). Regarding the test for comparison of lack of fit variance with pure error variance, "lack of fit $F$-value" of 1.78 and the $p$ value Prob $>F$ of 0.2532 imply that the lack of fit is nonsignificant $(p>0.05)$. Therefore, there is $25.32 \%$ chance that a "lack of fit $F$-value" could occur due to noise. In terms of variability of the observed and predicted responses, the $R^{2}$ obtained was of 0.9962 . Hence, the model proved to be solid for the prediction of the observed response $\left(R^{2}>0.80\right)$ (Joglekar and May 1987). Only $0.22 \%$ of the total variation could not be explained by the empirical model (Table 3 ). In addition, the signal to noise ratio was measured by Adeq Precision value, which was greater than 4 (53.625), indicating that this model can be used to navigate the design space. Regarding the significance of the factors used to build the second-order polynomial model, higher $F$-values leads to more significant parameters.

The optimal response was identified from Fig. 1 and Eq. 2: RPS glucose Eq. 1.50\% (w/v), EtOH 1.50\% (v/v) and YE/P $1.50 \%(\mathrm{w} / \mathrm{v})$ were chosen as the optimal concentrations (optimized RPS medium). Further fermentation experiments were made, in triplicate, to validate the optimal concentrations values (Table 4). The experimental values of BNC productivity (Table 4 ) were comparable to the predicted by the model $(p>0.05)$, although slightly lower, which may originate from variable batch-to-batch composition (Scott and Smith 1995; Kamali and Khodaparast 2015). Despite the decrease of BNC yield on experimental values (Table 4), a parity plot illustrating the distribution of experimental data and predicted values was drawn (Supplementary material, Figure S1). Data points are scattered along the diagonal line, also suggesting that the model was adequate to explain the $\mathrm{BNC}$ production yield within the studied experimental range.

\section{Production and characterization of the BNC nanocomposites}

As observed from the increase in the thickness, specific mass and polymer content of the BNC composites (Table 5), the exhaustion process effectively allowed the impregnation of $\mathrm{BNC}$ with different formulations of Persoftal (S), PEG and AESO. The obtained composites were characterized by ATR-FTIR, SEM, contact angle and mechanical properties. 


\section{ATR-FTIR analyses of BNC and BNC composites}

ATR-FTIR spectroscopy was used to characterize BNC and its composites. As seen in Fig. 2, the BNC spectrum shows characteristic peaks of cellulose, such as the $\mathrm{OH}$ stretching peak around $3344 \mathrm{~cm}^{-1}$, CH stretching of alkanes and asymmetrical stretching of $\mathrm{CH}_{2}$ at $2919 \mathrm{~cm}^{-1}$, OH bending of adsorbed water at $1650 \mathrm{~cm}^{-1}, \mathrm{CH}_{2}$ bending deformation at $1426 \mathrm{~cm}^{-1}$ and $1366 \mathrm{~cm}^{-1}$, OH deformation at $1334 \mathrm{~cm}^{-1}$, COC deformation modes and stretching vibrations at 1159$1107 \mathrm{~cm}^{-1}, \mathrm{COC}$ and $\mathrm{C}-\mathrm{OH}$ stretching vibration of the sugar ring at $1054-1029 \mathrm{~cm}^{-1}$ and $\mathrm{C}-\mathrm{OH}$ out-of-plane bending mode at $665 \mathrm{~cm}^{-1}$ (Araújo et al. 2018; Kawee et al. 2018; Yu et al. 2018; Wahid et al. 2019).

\section{Scanning electron microscopy}

To analyse the microstructure of the $\mathrm{BNC}$ and its composites, SEM micrographs of the surface as well as of the cross sections were collected. As illustrated in Fig. 3, the treatment of BNC membranes with different polymers led to significant changes in their morphology. The characteristic threedimensional nanofibrillar network was clearly observed on the surface of BNC. In the composites, BNC fibres are perfectly covered with the polymers and an increment of the fibres diameter is observed, associated with a more compact and uniform surface.
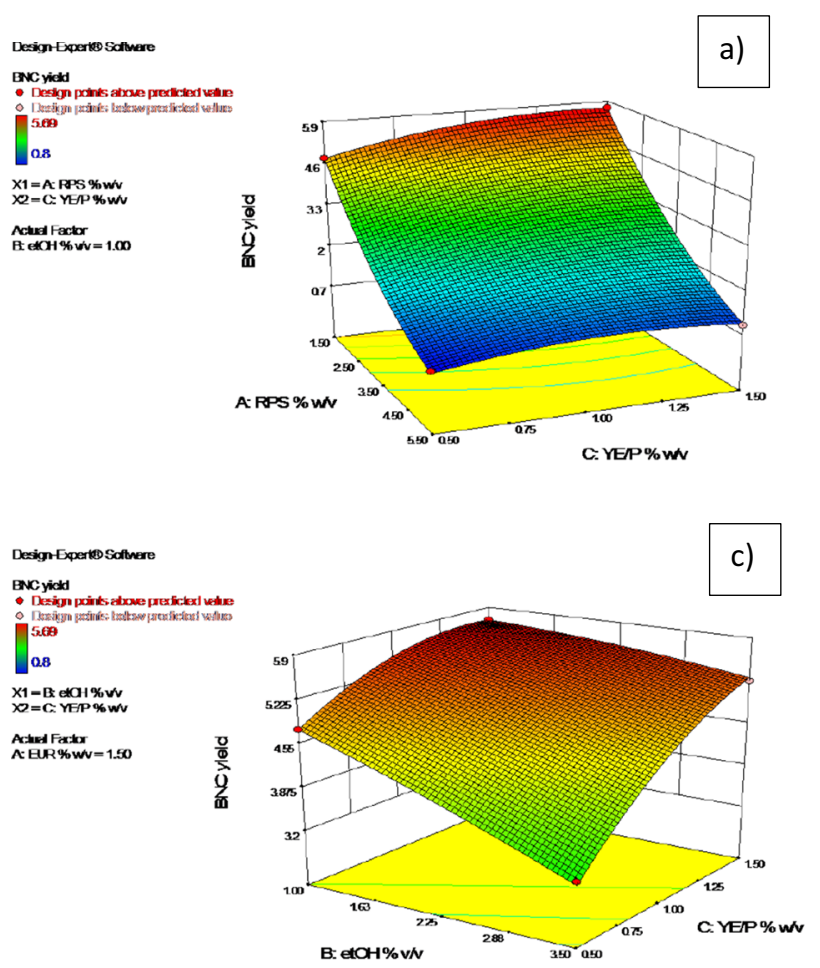

Fig. 1 3D graphs of K. xylinus ATCC 700178 RSM optimization with RPS culture medium; surface curve for BNC yield. a As a function of carbon source and ethanol. $\mathbf{b}$ As a function of carbon source and nitrogen
The cross-section micrographs of all nanocomposites displayed the typical lamellar morphology of BNC uniformly coated. Contrarily, for BNC-S/PEG400/AESO, a distinct layer was detected, where nanofibers cannot be clearly distinguished. The impregnation process is performed under agitation; thus, it is likely that colloidal particles of the several polymers of the formulation will form, facilitating its penetration in the BNC network.

\section{Wettability}

The water contact angles analysis (Fig. 4) further confirm the impregnation of the $\mathrm{BNC}$ membranes, changing its surface wettability and offering better hydrophobicity compared with pure BNC. The initial water contact angle increased in order BNC $<$ BNC-S < BNC-S/PEG400 < BNC-S/PEG400/AESO. The surface flatness of the composites increases in the same order, as qualitatively assessed by SEM.

\section{Mechanical properties}

SEM and FTIR analysis of the composites suggest that a good interfacial adhesion between the polymers mixture and BNC was achieved. Despite the high amounts of the polymers impregnated (Table 5), the behaviour of the composite is also governed by the BNC matrix. Compared with BNC, the mechanical properties of the composites were dramatically
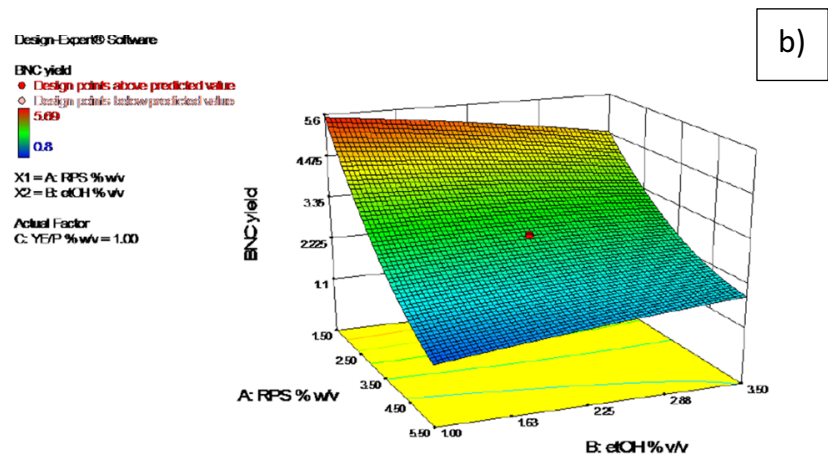

b)

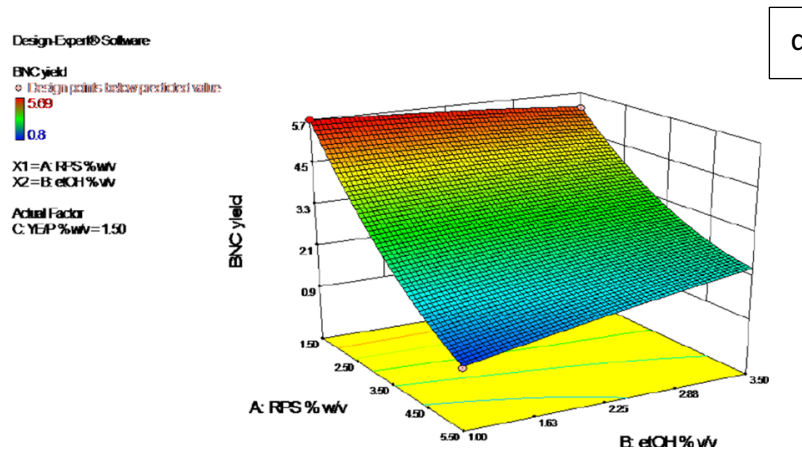

source. c As a function of nitrogen source and ethanol. d Graphical optimization graph as a function of carbon source and ethanol 
Table 3 ANOVA of CCD experiments

\begin{tabular}{|c|c|c|c|c|c|c|}
\hline Source & Sum of squares & df & Mean square & $\mathrm{F}$ Value & $P$ value $($ Prob $>\mathrm{F})$ & \\
\hline Model & 28.99 & 9 & 3.22 & 252.64 & $<0.0001$ & Significant \\
\hline A-RPS $\% w / v$ & 7.15 & 1 & 7.15 & 560.49 & $<0.0001$ & Significant \\
\hline B-etOH $\% v / v$ & 0.020 & 1 & 0.020 & 1.57 & 0.2658 & \\
\hline $\mathrm{C}-\mathrm{YE} / \mathrm{P} \% \mathrm{w} / \mathrm{v}$ & 3.26 & 1 & 3.26 & 255.46 & $<0.0001$ & Significant \\
\hline $\mathrm{AB}$ & 0.42 & 1 & 0.42 & 33.24 & 0.0022 & Significant \\
\hline $\mathrm{AC}$ & 0.11 & 1 & 0.11 & 8.91 & 0.0306 & Significant \\
\hline $\mathrm{BC}$ & 0.37 & 1 & 0.37 & 29.19 & 0.0029 & Significant \\
\hline $\mathrm{A}^{\wedge} 2$ & 0.51 & 1 & 0.51 & 40.01 & 0.0015 & Significant \\
\hline $\mathrm{B}^{\wedge} 2$ & 0.034 & 1 & 0.034 & 2.66 & 0.1640 & \\
\hline $\mathrm{C}^{\wedge} 2$ & 0.99 & 1 & 0.99 & 77.95 & 0.0003 & Significant \\
\hline Residual & 0.064 & 5 & 0.013 & & & \\
\hline Lack of Fit & 0.020 & 1 & 0.020 & 1.78 & 0.2532 & \\
\hline Pure Error & 0.044 & 4 & 0.011 & & & \\
\hline Cor Total & 29.05 & 14 & & & & \\
\hline $\mathrm{R}^{2}$ & & & & 0.9978 & & \\
\hline Adj $R^{2}$ & & & & 0.9939 & & \\
\hline Adeq Precision & & & & 53.625 & & \\
\hline
\end{tabular}

reduced, as shown in Fig. 5. The biggest obstacle for the practical application of composites is the poor stress transfer between the reinforcement and polymer matrix. Generally, the stress transfer between the two phases is strongly dependent on the degree of interfacial bonding (Wei and McDonald 2016). So, a lower tensile strength than that of neat BNC was expected, as PDMS is an amorphous polymer and BNC membrane is a highly crystalline material; also, the addition of other polymers to BNC membrane detracts the intermolecular hydrogen bonds between the BNC fibres, decreasing the tensile strength of the composite.

\section{Discussion}

In general, higher BNC yield was obtained using RPS hydrolysate as carbon source, than with HS medium, where pure glucose was used, suggesting that the RPS hydrolysate contains micro-ingredients that benefited the BNC production. Similar observations were recorded in the literature for other alternative substrates (Campano et al. 2016).

After ANOVA analysis of the RSM model, RPS hydrolysate and the nitrogen source (YE/P) parameters proved to be the more significant for BNC production with $K$. xylinus ATCC 700178, more than ethanol and the interactions between all parameters tested. Thus, the response surface model developed through CCD experiments (Table 3) may be considered satisfactory. The trustable results obtained allows an interpretation of individual and interactive effect of model terms on $\mathrm{BNC}$ production by the $3 \mathrm{D}$ graphs of $\mathrm{CCD}$ given in Fig. 1, which represents a saddle-like curve obtained for essential parameters.

Regarding RSM optimization results, the effect of RPS hydrolysate, ethanol and yeast extract/peptone concentrations on K. xylinus was analysed. Firstly, as observed in Fig.1a, the BNC yield increases with the decrease of the sugars' concentration. The same was noticed with ethanol (Fig. 1a and c), although this has been shown to favour BNC production by K. xylinus 700178 (Rodrigues et al. 2019). It has been shown that K. xylinum 700178 is not inhibited by high concentrations of carbon sources (Dahman et al. 2010; Bilgi et al. 2016; Rodrigues et al. 2019). Hence, the reduction of BNC production yield may be related to high amounts of potential inhibitors of bacterial growth in the RPS hydrolysate. Also, increasing glucose concentrations may lead to the production of gluconic acid by-product, gradually decreasing the medium's

Table 4 Optimization results and validation of CCD-RSM $K$. xylinus

\begin{tabular}{lllllr}
\hline $\begin{array}{l}\text { Validation } \\
\text { assays }\end{array}$ & $\begin{array}{l}\text { RPS gluc. eq. } \\
(\% \mathrm{~m} / \mathrm{v})\end{array}$ & EtOH $(\% \mathrm{v} / \mathrm{v})$ & $\mathrm{YE} / \mathrm{P}(\% \mathrm{~m} / \mathrm{v})$ & $\begin{array}{l}\text { Predicted } \\
\text { BNC yield }(\mathrm{g} / \mathrm{L})\end{array}$ & $\begin{array}{l}\text { Experimental } \\
\text { BNC yield }(\mathrm{g} / \mathrm{L})\end{array}$ \\
\hline 1 & 1.50 & 1.50 & 1.50 & 5.64 & $4.62 \pm 0.30$ \\
2 & 1.50 & 1.50 & 2.00 & 5.32 & $4.35 \pm 0.17$ \\
3 & 2.00 & 1.50 & 1.50 & 4.86 & $4.33 \pm 0.04$ \\
\hline
\end{tabular}


Table 5 Thickness, mass per unit area and polymers content of BNC composites

\begin{tabular}{llcl}
\hline Sample & $\begin{array}{l}\text { Thickness } \\
(\mathrm{mm})\end{array}$ & $\begin{array}{l}\text { Mass per unit } \\
\text { area }\left(\mathrm{g} \mathrm{m}^{-2}\right)\end{array}$ & $\begin{array}{l}\text { Polymers } \\
\text { content (\%) }\end{array}$ \\
\hline BNC & 0.48 & 325.5 & \\
BNC-S & 0.97 & 808.8 & 59.8 \\
BNC-S/PEG400 & 1.09 & 1012.4 & 67.9 \\
BNC-S/PEG400/AESO & 0.96 & 763.6 & 57.4 \\
\hline
\end{tabular}

$\mathrm{pH}$ values and inhibiting BNC production (Tsouko et al. 2015). On the other hand, the increase of YE/P leads to an increase of BNC yield of K. xylinus 700178 (Fig. 1b and c). Although a non-validated model was obtained, results from the RSM analysis suggest that RPS hydrolysate could be used at low concentrations $(1.5 \% \mathrm{w} / \mathrm{v})$ to achieve promising $\mathrm{BNC}$ yields, superior to those obtained with HS medium by almost two-fold. Since a much lower sugar concentration is being used $(1.5 \mathrm{vs} 4.0 \% \mathrm{w} / \mathrm{v})$, these results suggest that a further optimization may be possible, through the control of putative inhibitory compounds in the sugar syrup. This will be addressed in forthcoming work.

Regarding BNC composites, the spectra of both the surface and inner parts of the BNC-S composite showed the emergence of high-intensity peaks located at $1258 \mathrm{~cm}^{-1}$, corresponding to $\mathrm{Si}-\mathrm{CH}_{3}$, and located at $798 \mathrm{~cm}^{-1}$ which is attributed to $\mathrm{NH}_{2}$ wagging (Mohd et al. 2016). The spectrum of the inner part of the composite also shows a new peak, located at $1602 \mathrm{~cm}^{-1}$, assigned to $\mathrm{NH}_{2}$ bending vibration. The vibration band attributed to $\mathrm{Si}-\mathrm{O}-\mathrm{Si}$ and $\mathrm{Si}-\mathrm{O}-\mathrm{C}$ bond (1150$1135 \mathrm{~cm}^{-1}$ ), which corresponds to the condensation reaction between silanol and hydroxyl group of cellulose and selfcondensation reaction between silanol groups, is difficult to analyse as they overlap with the $\mathrm{C}-\mathrm{O}-\mathrm{C}$ skeletal vibration band. However, both spectra, surface and inner, show an increase in the intensity of these peaks, suggesting that the softener was grafted onto the $\mathrm{OH}$ functional groups of $\mathrm{BNC}$ (Mohd et al. 2016; Saini et al. 2016; Shao et al. 2017). An increase of the band at $2862-2961 \mathrm{~cm}^{-1}$, related to the $\mathrm{CH}_{2}$ stretching vibrations of the propyl group, was also observed (Shi et al. 2014; Saini et al. 2016; Shao et al. 2017).

In the BNC-S/PEG400 composite, the increase of some absorption bands can be attributed to PEG400, although they overlap with signals from cellulose and modified aminoPDMS. These bands are located at $3392-3346 \mathrm{~cm}^{-1}(\mathrm{OH}$ stretching), 2962-2873 cm $\mathrm{cm}^{-1}\left(\mathrm{CH}_{2}\right.$ stretching), $1409 \mathrm{~cm}^{-1}$ (asymmetric $\mathrm{CH}_{2}$ deformation), $1351 \mathrm{~cm}^{-1}$ ( $\mathrm{CH}_{2}$ wagging), $1258 \mathrm{~cm}^{-1}$ ( $\mathrm{CH}_{2}$ twisting), $1076-1006 \mathrm{~cm}^{-1}\left(\mathrm{CH}_{2}\right.$ symmetric deformation, $\mathrm{C}-\mathrm{O}-\mathrm{C}$ and $\mathrm{C}-\mathrm{OH}$ stretching) and $950 \mathrm{~cm}^{-1}$ and $864 \mathrm{~cm}^{-1}\left(\mathrm{CH}_{2}\right.$ rocking $)$. Another peak at $1721 \mathrm{~cm}^{-1}(\mathrm{C}=\mathrm{O}$ stretching) can be a result of ester linkages between PEG and the surface hydroxyl groups of BNC (Araki and Mishima 2014; Finocchio et al. 2014). With the incorporation of AESO, the main differences are observed in the spectrum of the inner part of the composite, where the characteristic peaks of the modified amino-PDMS at $794 \mathrm{~cm}^{-1}\left(\mathrm{NH}_{2}\right.$ wagging) and $1258 \mathrm{~cm}^{-1}\left(\mathrm{Si}-\mathrm{CH}_{3}\right)$ disappear. This may indicate that AESO is essentially concentrated inside the composite. As observed by SEM, the internal and surface layers of the composite display a different morphology.

We can speculate that the AESO mixture and modified amino-PDMS formed some agglomerates that remained mostly on the surface of the composite, whereas the AESO blend
Fig. 2 ATR-FTIR spectra of $\mathrm{BNC}$ and BNC composites

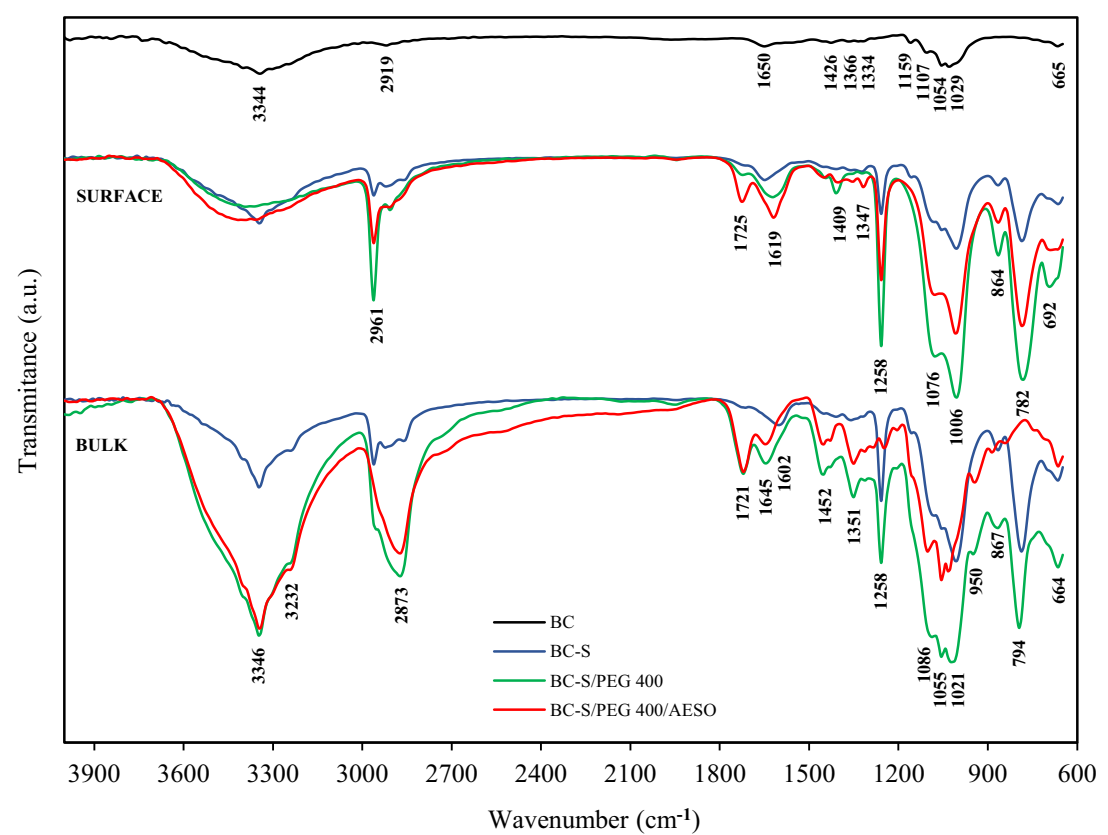


Fig. 3 SEM images of BNC and $\mathrm{BNC}$ composites
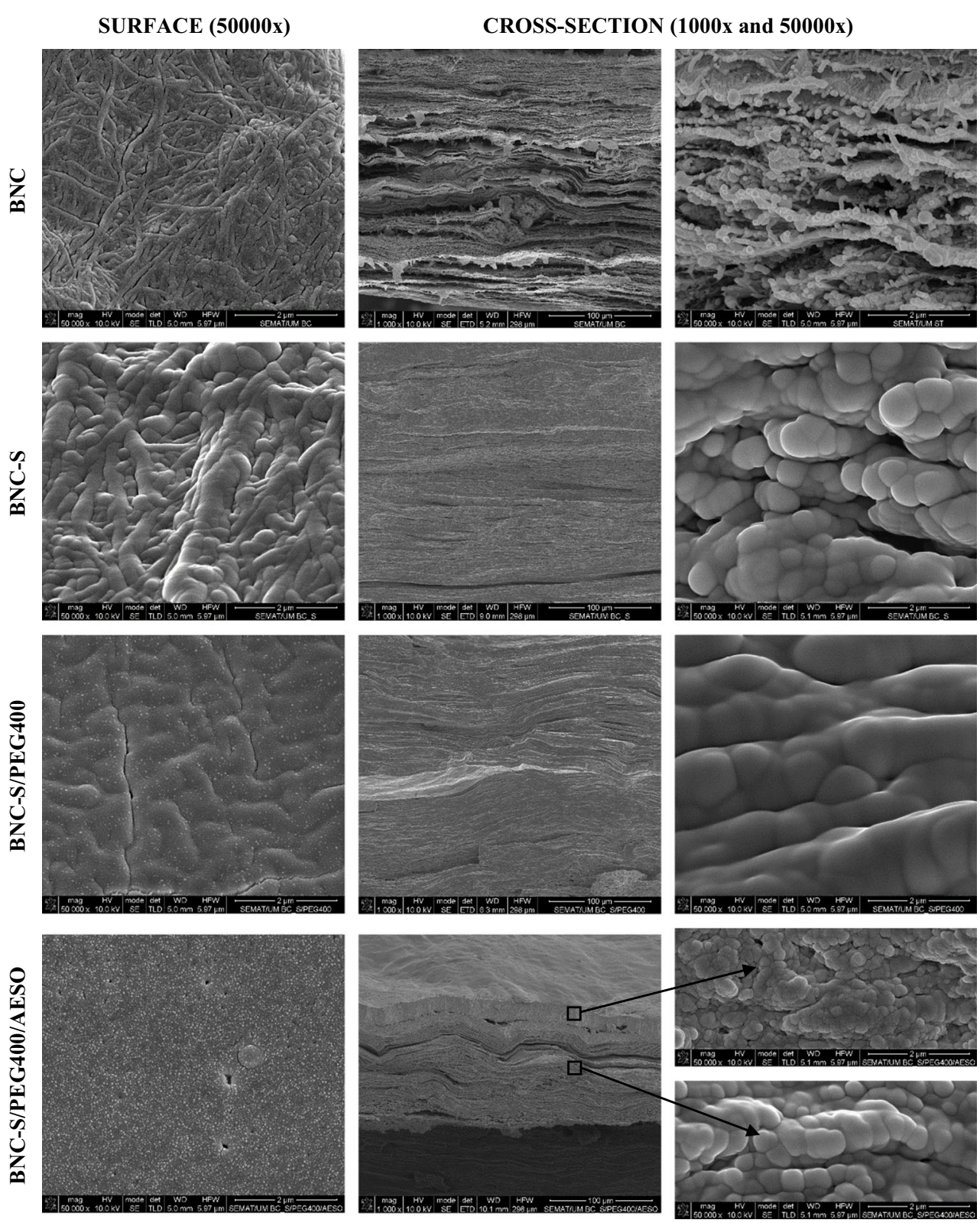
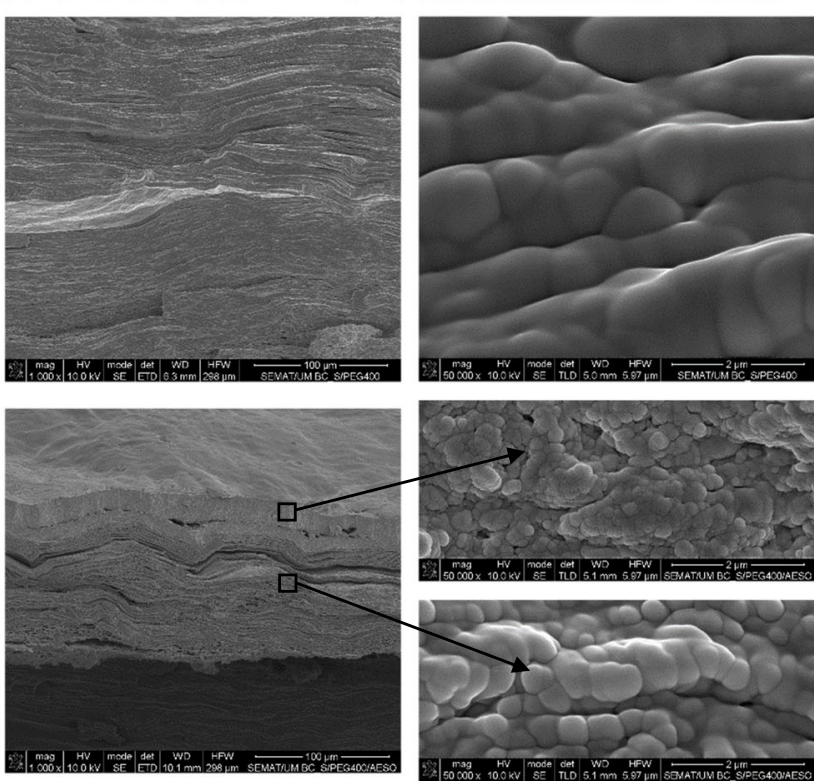

being in greater quantity penetrated to larger extent into the membrane. As shown by FTIR (Fig. 2), in the spectrum of the inner AESO composite, the presence of modified aminoPDMS was not detected. Upon drying, the agglomerates filled almost all of the pores provided a more compact surface where individual BNC fibres are not visible. Images at higher magnifications also provided evidence of the strong interfacial adhesion between BNC nanofibrils and the polymers, as shown by the cross-section images after fracturing and the homogeneous dispersion within the BNC network, individual cellulose fibres being no longer visible.

It is well accepted that the water-solid contact angle varies with a combined effect of both surface chemistry and roughness of the surface (Yousefi et al. 2018). Thus, although topography may partially justify the increase in contact angle (the higher porosity of $\mathrm{BNC}$ may contribute to a lower contact angle), this result is mainly related to the lower surface energy of the hydrophobic compounds impregnated with the composites. The more hydrophobic surface was obtained for BNC-S/ PEG400/AESO composite. The water contact angles for this surface was as high as $114.7^{\circ}$, indicating a low-energy surface with nonpolar functionalities from the incorporation of modified amino-PDMS and AESO resin. The water absorption/ spreading profile over time can be a result from the surface pores that allows the access to polar groups or a capillary effect, but again the AESO containing composite is more resistant to the absorption/spreading processes ( $\mathrm{Li}$ et al. 2019).

The introduction of PEG did not improve significantly the tensile strength but the elongation at break increased noticeably. PEG can act as a plasticizer, providing more space 
Fig. 4 Contact angle of $\mathrm{BNC}$ and BNC composites

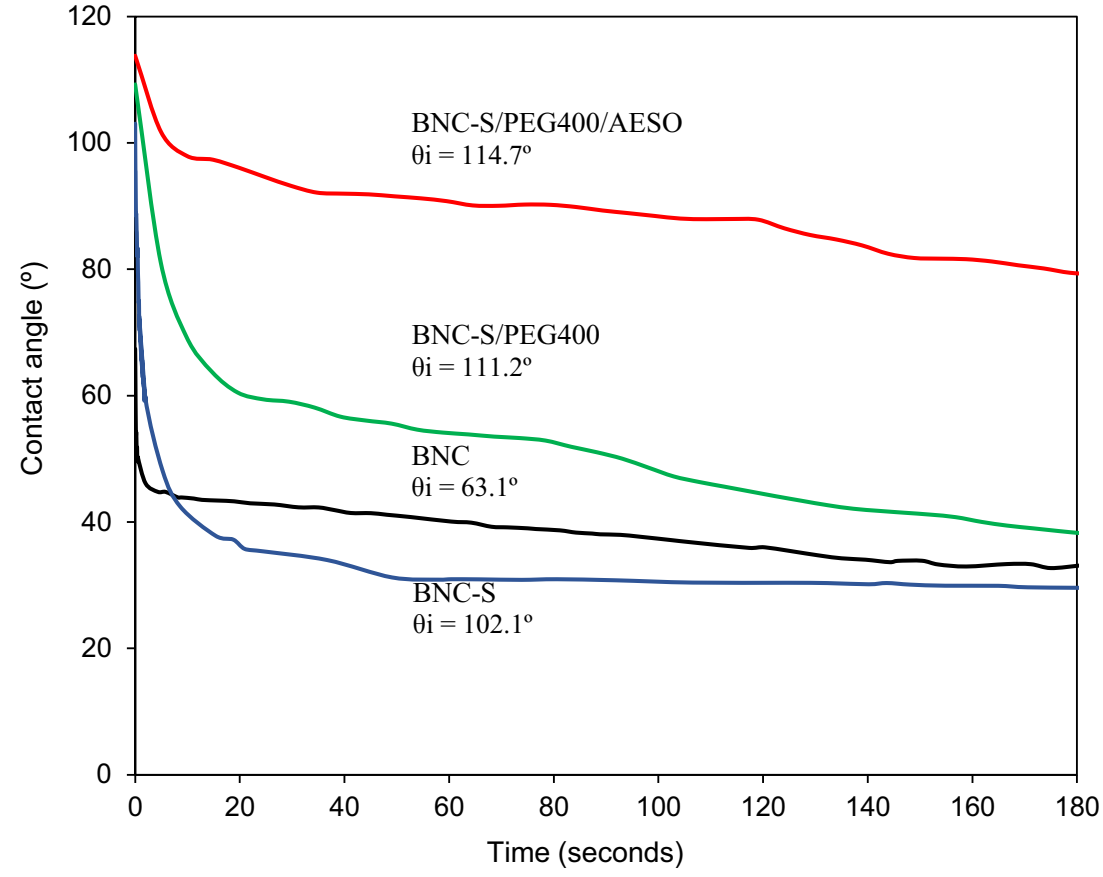

between the BNC fibres. On the other hand, when the AESO mixture was added, and since it was well dispersed in the matrix and, probably a better fibre-matrix interface bonding was formed, restricting the motion of PDMS molecule chains, which increased the stress transfer, resulting in a composite with higher tensile strength.

RSM-CCD analysis of BNC production by K. xylinus and medium sugar syrup obtained from waste non-recyclable paper fibres allowed building a second-order polynomial model predicting the BNC productivity. The highest BNC yield obtained after model analysis and validation were $4.62 \mathrm{~g} / \mathrm{L}$, using $1.5 \% \mathrm{~m} / \mathrm{v}$ of RPS hydrolysate, $1.5 \% \mathrm{~m} / \mathrm{v}$ of YE/P and $1.5 \%(\mathrm{v} / \mathrm{v}) \mathrm{EtOH}$.

New BNC-based composites with a high degree of sustainability were also successfully produced through exhaustion with modified amino-PDMS, PEG 400 and AESO. FTIR and SEM analyses provided evidence of the incorporation of these polymers into the BNC membrane, resulting on
Fig. 5 Stress-strain averaged curves of BNC and BNC composites obtained up to the rupture point

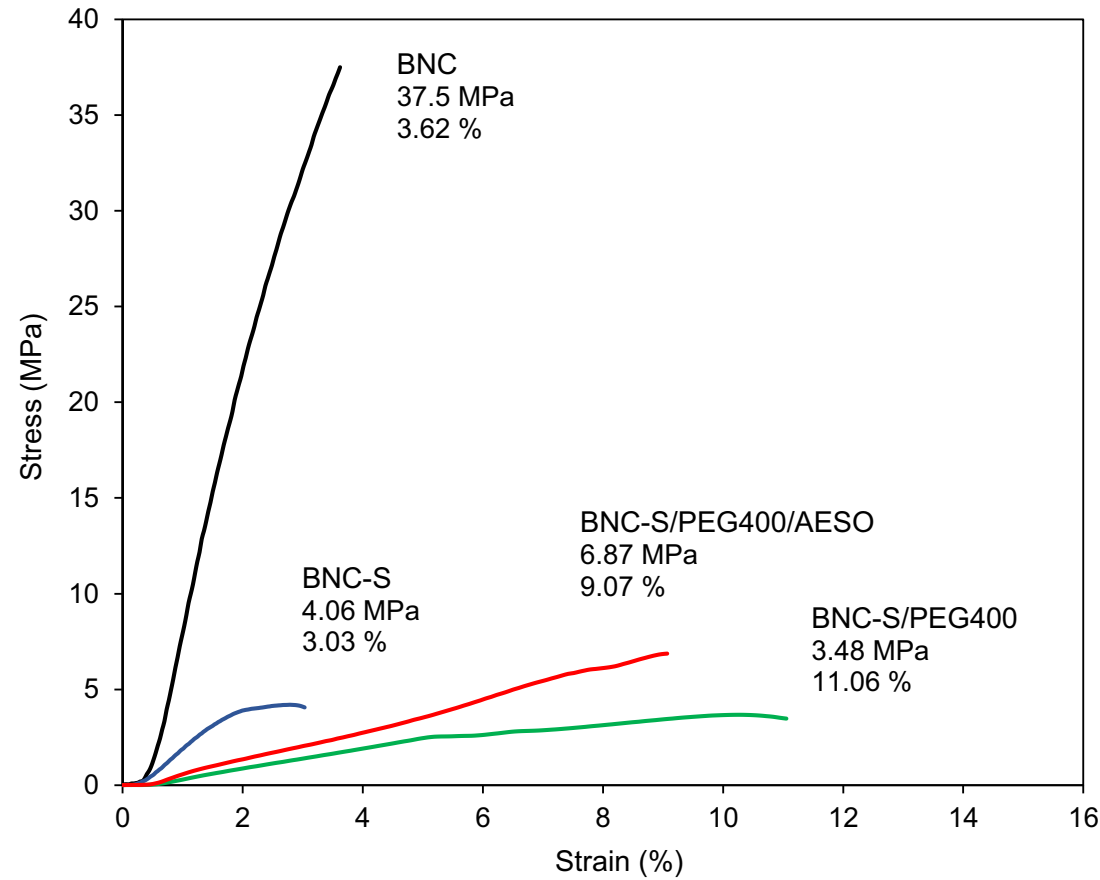


its hydrophobic performance. Although BNC has been used for the reinforcement of composites by several authors, there are very few studies using the intact BNC membrane obtained by static fermentation, thus keeping intact the $3 \mathrm{D}$ BNC network. This promising concept will be further exploited in future work.

Acknowledgements The authors thank Europac (Viana do Castelo, Portugal) for the supply of RPS.

Funding information This study was supported by the Portuguese Foundation for Science and Technology (FCT) under the scope of the strategic funding of UID/BIO/04469/2019, UID/CTM/00264/2019; the project SkinShip - "Dispositivo de microfluídica inovador baseado em celulose capaz de suportar a modelação 3D de pele", with reference PTDC/BBB-BIO/1889/2014 (funded by the European Regional Development Fund (FEDER) through the Competitiveness and Internationalization Operational Program - COMPETE 2020, the Lisbon Regional Operational Program and by National Funds through the FCT - Foundation for Science and Technology under the project POCI-01-0145-FEDER-016595); and Multibiorefinery PAC (SAICTPAC/0040/2015) and BUILD - Bacterial cellulose Leather (NORTE-01-0247-FEDER-003435) and BioTecNorte operation (NORTE-01-0145-FEDER-000004) funded by the European Regional Development Fund under the scope of Norte2020 - Programa Operacional Regional do Norte.

\section{Compliance with ethical standards}

Conflict of interest The authors declare that they have no conflict of interest.

Ethical approval This article does not contain any studies with human participants or animals performed by any of the authors.

\section{References}

Araki J, Mishima S (2014) Steric stabilization of "charge-free" cellulose nanowhiskers by grafting of poly (ethylene glycol). Molecules 20(1):169-184

Araújo IMS, Silva RR, Pacheco G, Lustri WR, Tercjak A, Gutierrez J, Júnior JRS, Azevedo FHC, Figuêredo GS, Vega ML, Ribeiro SJL, Barud HS (2018) Hydrothermal synthesis of bacterial cellulosecopper oxide nanocomposites and evaluation of their antimicrobial activity. Carbohydr Polym 179:341-349

Bilgi E, Bayir E, Sendemir-Urkmez A, Hames EE (2016) Optimization of bacterial cellulose production by Gluconacetobacter xylinus using carob and haricot bean. Int J Biol Macromol 90:2-10

Campano C, Balea A, Blanco A, Negro C (2016) Enhancement of the fermentation process and properties of bacterial cellulose: a review. Cellulose 23(1):57-91

Chawla PR, Bajaj IB, Survase SA, Singhal RS (2009) Microbial cellulose: fermentative production and applications. Food Technol Biotechnol 47(2):107-124

Chen G, Wu G, Alriksson B, Wang W, Hong FF, Jönsson LJ (2017) Bioconversion of waste fiber sludge to bacterial nanocellulose and use for reinforcement of CTMP paper sheets. Polymers 9(9):458

Cheng Z, Yang R, Liu X, Liu X, Chen H (2017) Green synthesis of bacterial cellulose via acetic acid pre-hydrolysis liquor of agricultural corn stalk used as carbon source. Bioresour Technol 234:8-14
Dahman Y, Jayasuriya KE, Kalis M (2010) Potential of biocellulose nanofibers production from agricultural renewable resources: preliminary study. Appl Biochem Biotechnol 162(6):1647-1659

Fan X, Gao Y, He W, Hu H, Tian M, Wang K, Pan S (2016) Production of nano bacterial cellulose from beverage industrial waste of citrus peel and pomace using Komagataeibacter xylinus. Carbohydr Polym 151:1068-1072

Finocchio E, Cristiani C, Dotelli G, Stampino PG, Zampori L (2014) Thermal evolution of PEG-based and BRIJ-based hybrid organoinorganic materials. FT-IR studies. Vib Spectrosc 71:47-56

Gomes D, Domingues L, Gama M (2016) Valorizing recycled paper sludge by a bioethanol production process with cellulase recycling. Bioresour Technol 216:637-644

Hestrin S, Schramm M (1954) Synthesis of cellulose by Acetobacter xylinum. 2. Preparation of freeze-dried cells capable of polymerizing glucose to cellulose. Biochem J 58(2):345-352

Hong F, Zhu YX, Yang G, Yang XX (2011) Wheat straw acid hydrolysate as a potential cost-effective feedstock for production of bacterial cellulose. J Chem Technol Biotechnol 86(5):675-680

Hong F, Guo X, Zhang S, Han S-f, Yang G, Jönsson LJ (2012) Bacterial cellulose production from cotton-based waste textiles: enzymatic saccharification enhanced by ionic liquid pretreatment. Bioresour Technol 104:503-508

Huang C, Guo H-J, Xiong L, Wang B, Shi S-L, Chen X-F, Lin X-Q, Wang C, Luo J, Chen X-D (2016) Using wastewater after lipid fermentation as substrate for bacterial cellulose production by Gluconacetobacter xylinus. Carbohydr Polym 136:198-202

Joglekar AM, May AT (1987) Product excellence through experimental design. In Graf E, Saguy IS, eds. Food Product Development from Concept to the Market Place. AVI Publisher, New York, pp 211-230

Kamali M, Khodaparast Z (2015) Review on recent developments on pulp and paper mill wastewater treatment. Ecotoxicol Environ Saf 114:326-342

Kawee N, Lam NT, Sukyai P (2018) Homogenous isolation of individualized bacterial nanofibrillated cellulose by high pressure homogenization. Carbohydr Polym 179:394-401

Kim S-J, Dwiatmoko AA, Choi JW, Suh Y-W, Suh DJ, Oh M (2010) Cellulose pretreatment with 1-n-butyl-3-methylimidazolium chloride for solid acid-catalyzed hydrolysis. Bioresour Technol 101(21):8273-8279

Klemm D, Schumann D, Udhardt U, Marsch S (2001) Bacterial synthesized cellulose - artificial blood vessels for microsurgery. Prog Polym Sci 26(9):1561-1603

Lee KY, Buldum G, Mantalaris A, Bismarck A (2014) More than meets the eye in bacterial cellulose: biosynthesis, bioprocessing, and applications in advanced fiber composites. Macromol Biosci 14(1): $10-32$

Li L, Zhou Z-H, Yang B, Ji X, Huang H-D, Zhong G-J, Ling X, Li Z-M (2019) Robust cellulose nanocomposite films based on covalently cross-linked network with effective resistance to water permeability. Carbohydr Polym 211:237-248

Marques S, Alves L, Roseiro J, Gírio F (2008a) Conversion of recycled paper sludge to ethanol by SHF and SSF using Pichia stipitis. Biomass Bioenergy 32(5):400-406

Marques S, Santos JA, Gírio FM, Roseiro JC (2008b) Lactic acid production from recycled paper sludge by simultaneous saccharification and fermentation. Biochem Eng J 41(3):210-216

Marques S, Alves LM, Gírio FM, Santos JAL, Roseiro JC (2009) Biological upgrading of wastes from the pulp and paper industry. NWBC, Helsinki, Finland, 2-4 September

Mohd NH, Ismail NFH, Zahari JI, Fathilah W, Kargarzadeh H, Ramli S, Ahmad I, Yarmo MA, Othaman R (2016) Effect of aminosilane modification on nanocrystalline cellulose properties. J Nanomater 2016:1-8

Müller A, Ni Z, Hessler N, Wesarg F, Müller FA, Kralisch D, Fischer D (2013) The biopolymer bacterial nanocellulose as drug delivery 
system: investigation of drug loading and release using the model protein albumin. J Pharm Sci 102(2):579-592

Nimeskern L, Ávila HM, Sundberg J, Gatenholm P, Müller R, Stok KS (2013) Mechanical evaluation of bacterial nanocellulose as an implant material for ear cartilage replacement. J Mech Behav Biomed Mater 22:12-21

Prasetyo J, Park EY (2013) Waste paper sludge as a potential biomass for bio-ethanol production. Korean J Chem Eng 30(2):253-261

Rajwade J, Paknikar K, Kumbhar J (2015) Applications of bacterial cellulose and its composites in biomedicine. Appl Microbiol Biotechnol 99(6):2491-2511

Rodrigues AC, Fontão AI, Coelho A, Leal M, da Silva FAS, Wan Y, Dourado F, Gama M (2019) Response surface statistical optimization of bacterial nanocellulose fermentation in static culture using a low-cost medium. New Biotechnol 49:19-27

Saini S, Belgacem MN, Salon M-CB, Bras J (2016) Non leaching biomimetic antimicrobial surfaces via surface functionalisation of cellulose nanofibers with aminosilane. Cellulose 23(1):795-810

Scott GM, Smith A (1995) Sludge characteristics and disposal alternatives for the pulp and paper industry. Tappi Intern. Environ. Conf., Tappi Press, pp 269-279

Shao W, Wu J, Liu H, Ye S, Jiang L, Liu X (2017) Novel bioactive surface functionalization of bacterial cellulose membrane. Carbohydr Polym 178:270-276

Shi Z, Zhang Y, Phillips GO, Yang G (2014) Utilization of bacterial cellulose in food. Food Hydrocoll 35:539-545

Sluiter A, Hames B, Ruiz R, Scarlata C, Sluiter J, Templeton D, Crocker D (2008) Determination of structural carbohydrates and lignin in biomass. LAP 1617:1-16
Tsouko E, Kourmentza C, Ladakis D, Kopsahelis N, Mandala I, Papanikolaou S, Paloukis F, Alves V, Koutinas A (2015) Bacterial cellulose production from industrial waste and by-product streams. Int J Mol Sci 16(7):14832-14849

Wahid F, Hu X-H, Chu L-Q, Jia S-R, Xie Y-Y, Zhong C (2019) Development of bacterial cellulose/chitosan based semiinterpenetrating hydrogels with improved mechanical and antibacterial properties. Int J Biol Macromol 122:380-387

Wei L, McDonald A (2016) A review on grafting of biofibers for biocomposites. Materials (Basel) 9(4):303

Yamanaka S, Watanabe K, Kitamura N, Iguchi M, Mitsuhashi S, Nishi Y, Uryu M (1989) The structure and mechanical properties of sheets prepared from bacterial cellulose. J Mater Sci Mater Med 24(9): 3141-3145

Yousefi B, Gharehaghaji AA, Asgharian Jeddi AA, Karimi M (2018) The combined effect of wrinkles and noncircular shape of fibers on wetting behavior of electrospun cellulose acetate membranes. J Polym Sci B Polym Phys 56(13):1012-1020

Yu B, Cheng H, Zhuang W, Zhu C, Wu J, Niu H, Liu D, Chen Y, Ying H (2018) Stability and repeatability improvement of horseradish peroxidase by immobilization on amino-functionalized bacterial cellulose. Process Biochem 79:40-48

Yudianti R, Karina M (2012) Development of nanocomposites from bacterial cellulose and poly (vinyl alcohol) using casting-drying method. Procedia Chem 4:73-79

Publisher's note Springer Nature remains neutral with regard to jurisdictional claims in published maps and institutional affiliations. 